\title{
LA CUESTION DE LAS ISLAS MALVINAS
}

Ana Ochoa Reyes

El trabajo se inicia realizando un cuidadoso rastreo de los principales hechos históricos y de ocupación en torno a las Islas Malvinas, desde su descubrimiento en el siglo XVI, hasta los años problemáticos del siglo XIX en que los territorios son tomados colonialmente por Inglaterra.

El segundo capitulo hace un análisis critico de los diferentes títulos de soberania que, a partir de los hechos anteriores, reclaman para si la Gran Bretaña y la República Argentina. Del estudio se concluye que los titulos legítimos corresponden a la Argentina.

Finalmente, se hace una extensa referencia al tratamiento que el problema de las Islas Malvinas ha tenido en el debate internacional, preferentemente en las Naciones Unidas. Detalle especial se hace en relación a los principios de la Descolonización, la Libre determinación y la Integridad Territorial, aplicados al caso bajo estudio.

\section{I.- ANTECEDENTES HISTORICOS DE LA CONTROVERSIA}

A. El Descubrimiento de las Islas (1)

Es a principios del S. XVI que las Islas Malvinas comienzan a figurar en los mapas del viejo continente. Sin embargo. existen dudas respecto a su descubrimiento.

Algunos historiadores atribuyen dicha hazaña al piloto Esteban Gómez de la expedición de Magallanes en el año de 1520.

(1) Veáse Ricardo CARRASCO, En Anuario de la Sociedad Cubana de Dereccho, Vol. 21 (La Habana, 1949), pp. 186-191. 
Otros consideran que la labor cartográfica realizada por el experto Diego de Rivera en 1527 a pedido del Emperador Carlos $\mathrm{V}$ de Alemania y España. la cual contenía ya un dibujo algo impreciso de las Islas, estuvo basada en los datos obtenidos por la expedición exploradora de Américo Vespucio del año 1501. De otro lado, las fuentes inglesas señalan a Jhon Davis como el primer navegante en avistar las islas en el año de 1592. Cabe aclarar sin embargo, que el nombre con que hoy se conoce a las islas, tanto en su versión inglesa como en la española, no proviene del hecho de su descubrimiento, sino de otras circunstancias.

En el año de 1690 , en una escala de su recorrido por los mares del sur, el capitán inglés John Strong dio a las islas el nombre de Falkland en honor a Luscius Carey, visconde de Falkland, quien en ese entonces ocupaba el puesto de tesorero de la marina real inglesa. Algunos años más tarde, marinos franceses que viajaban constantemente del puerto de St. Malo al Rio de la Plata con fines comerciales, decidieron bautizar las islas con el nombre de Malouines, de donde deriva el actual nombre español de Malvinas.

Sea cual fuere la verdad histórica con respecto al descubrimiento de las islas, lo que no admite dudas es el hecho de que sus primeros ocupantes y colonizadores fueron los franceses.

\section{B. La Ocupación Francesa}

\section{La Expedición de Bougainville}

En 1763, un grupo de pescadores franceses guiados por Louis Antoine de Bougainville parte hacia las Islas Malvinas en la goleta L'aigle y la corbeta Sphinx, logrando llegar a su punto de destino en febrero de 1764. Esta expedición que cuenta con el visto bueno del gobierno francés (2) toma solemne posesión de las islas en nombre del rey de Francia, el 5 de abril del mismo año.

(2) J.H. PARRY, Trade and Dominion. The European Overseas Empires in the Eighteenth Century. (Wiedenfeld and Nicholson, 1971), p. 131. 
El asentamiento francés fundado en la Malvina Oriental Hlevó el nombre de Port Louis en honor al soberano francés Luis XV.

La primera noticia pública de la ocupación francesa aparece en la "Gazette de la Haye" el 13 de agosto de 1764 (3).

Fundada la colonia, Bougainville vuelve a Francia dejando Port Louis al mando de su primo Nerville, quien luego fuera el primer gobernador de las islas.

\section{La Reclamación Española}

Una vez noticiada la Corte de Madrid de la ocupación francesa resuelve iniciar las negociaciones con Paris por intermedio de su Ministro de Relaciones Exteriores, el Marquez de Grimaldi, para obtener el reconocimiento de sus derechos de soberania sobre el archipiélago malvinense, derechos estos que provenian del contenido de una serie de Tratados celebrados por las potencias maritimas europeas de la época, con el objeto de delimitar las regiones sobre las que cada una de ellas tenia derechos territoriales. A la vez, España ofrece abonar todos los gastos que hubiera demandado la fundación de la colonia francesa. El rey francés reconoce los derechos españoles y acepta la compensación de 618,108 libras esterlinas. Acto seguido, Bougainville parte a Madrid y el 4 de febrero de 1766 firma en San Idelfonso el acta de entrega de la posesión francesa en las Isias Malvinas al gobierno español, recibiendo a cambio la suma compensatoria correspondiente a los gastos efectuados. Al respecto, Bougainville, en un pasaje de su libro titulado "Viaje alrededor del Mundo por la fragata del rey" escribe:

"Habiendo reconocido Francia el derecho de su Majestad Católica sobre las Islas Malvinas, el Rey de España, por un principio de derecho político conocido de todo el mundo, no debia ningún reembolso de estos gastos. Sin embargo, como adquiría los navios, mercaderia.... que componian nuestros establecimientos. este monarca tan justo como generoso, ha querido reembol-

(3) Alfredo BRUNO BOLOGNA, En Estudios de Derecho, No 96, (Medellin, 1979), p. 407. 
sarnos nuestros adelantos, y la suma supradicha nos ha entregado por sus tesoreros (4)".

El traspaso de la posesión del establecimiento se hace efectivo el $1^{9}$ de abril de 1767, luego de 3 años de ocupación francesa. Previamente, el 4 de octubre de 1766, el gobierno español había dictado una Real Cédula que declaraba a las Malvinas dependientes de la Capitania General de Buenos Aires y se nombraba a don Felipe Ruiz Puente como su gobernador.

Los españoles bautizan a su nuevo establecimiento con el nombre de Puerto Soledad.

Es asi que de manera amistosa y con el reconocimiento del derecho español sobre las islas, quedó definitivamente resuelto el litigio franco-español.

\section{La Ocupación Inglesa}

Por recomendación del almirante George Anson, quien de 1740 a 1744 realizara un viaje de circunnavegación por el mundo, el gobierno inglés comienza a considerar de gran importancia el establecer una base naval en las Malvinas. En 1748 el Almirantazgo proyecta la expedición con fines cientificos. Enterado el gobierno español de dichos proyectos se opone por considerarlo atentatorio a su soberania territorial. Los ingleses alegan que la expedición no buscaba perturbar los derechos de España, sino simplemente explorar aquellas regiones remotas (5). Al respecto, el Ministro español encargado de las negociaciones entre ambas naciones comentaba en tono irónico que "si el proyectado viaje inglés era con el objeto de formar establecimiento seria una hostilidad para España, dueña de las islas, pero que si era el de una curiosidad, el daria cuantas noticias se deseasen, sin necesidad de entrar en gastos de expediciones para satisfacerlas (6).

(4) Ibid p. 408.

(5) CARRASCO, ob. cit. p. 193.

(6) Raúl MARTINEZ MORENO, En Revista de la Universidad de Córdoba, Año VI (1965), p. 512. 
Los resultados de las negociaciones entre ambas naciones son descritos por el autor inglés Miller en la "Historia del Reinado de Jorge III":

"...cuando el mismo Lord Anson fue puesto al frente del Almirantazgo, se hicieron preparativos para ejecutar un plan, pero se opuso a ello el Rey de España por pertenecerle las islas. A la vista de esto, los ingleses desistieron de la empresa (7)".

Es decir que debido a una buena gestión diplomática apoyada en los tratados que delimitaban las zonas bajo soberanía tanto de España como de Gran Bretaña, el proyecto Anson queda abandonado en 1750 .

Es importante destacar que la verdadera cuestión debatida en las negociaciones anglo-españolas fue el derecho de Gran Bretaña a "penetrar" en las regiones del Atlántico Sur y no su derecho a establecerse en las islas.

\section{Expedición de John Byron}

Luego de transcurridos 15 años de haber sido desechado el proyecto Anson, el gobierno inglés decide retomarlo y confia la expedición compuesta por los buques Delphin y Temar al Comodoro John Byron.

Byron parte de Inglaterra el mes de junio de 1764, cuando aún no había sido publicada la Revista Gazette de la Haye que informaba sobre la ocupación francesa de las islas, y llega a la Malvina Occidental en enero de 1765 tomando posesión del lugar en nombre del Rey Jorge III y denominándolo Port Egmont.

En el mes de setiembre del año siguiente se extienden instrucciones secretas al capitán Mac Bride a cargo de la segunda expedición inglesa destinada a las Malvinas, para que evite cuidadosamente proceder con medidas de hostilidad y violencia en las islas, salvo en Port Egmont, donde sí se le ordenaba defender y mantener la posesión efectuada (8).

(7) CARRASCO, ob. cit. p. 193.

(8) BRUNO BOLOGNA, ob. cit. p. 417. 
El Capitán Mac Bride junto con unos 30 hombres más, desembarca en las Malvinas en el mes de enero de 1766, cuando los franceses ya llevaban casi 2 años de ocupar el otro lado del archipiélago. La ocupación continúa hasta el 10 de junio de 1770. fecha en que España envia al capitán de navio Juan Ignacio de Madariaga al frente de una escuadra para que desaloje por la fuerza a los colonos ingleses de Port Egmont.

\section{Reacción de España ante la Ocupación Inglesa}

Desde que España recibiera la posesión del archipiélago de manos de los franceses, tenia noticias de la existencia de un establecimiento oculto inglés. Por ello, la Corte de Madrid resuelve instruir a su Embajador en Inglaterra, el Príncipe de Masserano, para que efectúe el reclamo pertinente. Dicho reclamo se apoya en el artículo VIII del Tratado de Utrech de 1713, en virtud del cual Inglaterra se habia comprometido a asistir a España para que ésta mantuviera las Indias Occidentales tal y como se hallaban delimitadas bajo el reinado de Carlos II (9). Al no prosperar la gestión diplomática, el gobierno español ordena al gobernador de Buenos Aires, Francisco de Bucarelli y Ursúa que no permita ningún establecimiento en las islas y que si estos ya existiesen que procediera a desalojarlos por la fuerza (10). España estaba decidida a defender, incluso con las armas, la integridad de sus adquisiciones territoriales.

Una vez informado Bucarelli de la ubicación del establecimiento inglés, decide entrevistarse con el comandante de la escuadra del Rio de la Plata, don Juan Ignacio de Madariaga para ponerse de acuerdo sobre las medidas a adoptar. Se resuelve ordenar al capitán de fragata don Fernando de Rubalcava que zarpe con destino al puerto inglés para exigir el retiro de la guarnición pirata. El 20 de febrero de 1770 Rubalcava cumple con enviar una nota al capitán Antonio Hunt, quien en esos momentos se hallaba al mando del barco inglés Tamer. Hunt no accede a retirarse alegando que él protegería las islas que por derecho de descubrimiento pertenecian al rey de Inglaterra. A

(9) CARRASCO, ob. cit. p. 194.

(10) BRUNO BOLOGNA, ob. cit. p. 426. 
su vez exhorta a los españoles a que sean ellos quienes procedan a evacuar las islas, Rubalcava regresa a Puerto Soledad decepcionado por haber fracasado en su misión y relata lo acontecido a Bucarelli, quien de inmediato decide enviar una $2^{\text {a }}$ expedición a mando de Madariaga para que de una vez por todas desaloje a los ingleses.

Madariaga atraca en Port Egmont el 6 de junio de 1770 y recurre primeramente a la intimación al desalojo, mas, al encontrarse frente a una guarnición inglesa hostil decide abrir fuego. El día 10 del mismo mes los británicos son derrotados y se ven obligados a firmar la capitulación (11).

\section{Negociaciones Madrid-Londres}

Enterado de los hechos acaecidos el 10 de junio en Port Egmont el gobierno inglés no hace esperar sus airadas protestas y se prepara para un posible enfrentamiento bélico. Carlos III de España recurre de inmediato al rey Luis XVi con quien tenia un pacto de familia, pero éste le hace saber que Francia no se hallaba en condiciones de intervenir en una guerra colonial contra Inglaterra (12). Todo lo que ofrece es actuar como mediador para buscar una posible fórmula de conciliación. En vista de esto, España se ve obligada a asumir una actitud más pacifista en sus negociaciones con Inglaterra. Ilustrativa de esta actitud es la negativa del Príncipe de Masserano de aceptar cualquier participación oficial de España en el desalojo de los marinos ingleses de Port Egmont, sosteniendo a la vez que dicha acción habia sido ordenada por Bucarrelli a iniciativa propia (13).

El soberano inglés, Jorge III, manifestaba su total desaprobación por los procedimientos empleados por los súbditos españoles y exigía que las cosas en Port Egmont se restituyesen al estado en que se hallaban antes del 10 de junio de 1770. Esta petición resumía el sentir del pueblo inglés que consideraba haber sido ofendido en su honor.

(11) CHAMBER'S ENCYCLOPAEDIA, Falk'and Island, Vol. 5, (Pergamon Press LTD, 1967), p. 549.

(12) David HORN, Great Britain and Europe in the Eigteenth Century, (Claredon Press, Oxford, 1967), p. 297.

(13) CARRASCO, ob. cit. p. 201. 
En una conversación sostenida entre el Embajador francés en Gran Bretaña y el primer Ministro inglés Lord Frederick North, éste último expresaba que Inglaterra no deseaba conservar las islas, las cuales no tenían ningún valor para ellos, y que si España daba la satisfacción reclamada ellos iban seguramente a evacuarlas (14).

Las negociaciones continúan en Londres y finalmente Masserano formula una propuesta que es aceptada por el gobierno inglés. Se trata de una declaración en la cual se desagraviaba a Inglaterra y cuyo texto pasamos a transcribir:

"SMC reprueba la sobredicha violenta empresa, y por lo tanto el Principe de Masserano declara que su dicha $\mathrm{MC}$ se obliga a dar orden inmediata para que se repongan las cosas en la Gran Malvina y Puerto Egmont en el mismo estado en que se hallaban antes del 10 de junio de 1770 . El principe declara al mismo tiempo, en nombre del Rey su amo, que la promesa que hace Su dicha MC de restituir a SM Británica la posesión del fuerte y puerto llamado de Egmont, no perjudica de modo alguno la cuestión de derecho anterior de soberania de las Islas Malvinas, por otro nombre de Falkland. En londres, a 22 de Enero de 1771. Firmado: El Principe de Masserano (15)".

De esta manera, a la vez que desagravia a Inglaterra. España hace expresa reserva de su derecho de soberanía sobre las Islas Malvinas.

Acto seguido, los ingleses retornan a Port Egmont.

\section{El Pacto Secreto}

Muchos historiadores afirman la existencia de un pacto secreto entre España e Inglaterra por el cual esta última se comprometia a evacuar Port Egmont luego de transcurrido un tiempo prudencial para calmar a la violentada opinión pública inglesa (16). En efecto, el 22 de mayo de 1774, luego de 3 años de

(14) BRUNO BOLOGNA, ob. cit. p. 415 .

(15) CARRASCO, ob. cit. p. 202.

(16) PARRY, ob. cit. p. 132. 
ocupación, los ingleses deciden abandonar su campamento con el fútil pretexto de hacer economia. Al partir dejan una placa en la cual se proclama el derecho de soberanía de SMB sobre las islas.

Después de revisar el contenido de la documentación extraida del Archivo Histórico de Madrid por el estudioso argen. tino Raúl Martinez Moreno (17) se puede concluir que el pacto secreto antes mencionado verdaderamente existió.

Luego de desocupar las islas, no hubo ya ningún intento por parte de los ingleses de retornar a ellas y asi pudo España mantener un dominio absoluto del archipiélago hasta producida la Independencia de la nación argentina.

\section{La Toma de Posesión Argentina}

1. Actos de Posesión sobre las Islas

Por la Revolución de Mayo de 1810, Argentina toma posesión de las Provincias Unidas del Río de la Plata y en 1816 proclama su independencia de España en el Congreso de Tucumán.

Los distintos gobiernos provisionales de la naciente República realizan actos de dominio sobre el archipiélago malvinense entre los años de 1811 y 1817 (18). Luego, en 1820, se nombra oficialmente primer gobernante de las islas al coronel David Jewet, quien se instala en Puerto Soledad al mando de una pequeña guarnición. Nueve años más tarde se designa gobernador a Luis Vernet, quien llegando a las islas dicta una serie de ordenanzas prohibitivas de pesca indiscriminada. Es en estos momentos que viendo sus intereses afectados, Gran Bretaña protesta por primera vez expresando la incompatibilidad de la actitud

(17) Extraido de: MARTINEZ MORENO, ob cit. pp. 526-543.

(18) MINISTERIO DE RR.EE. Y CULTO DE ARGENTINA, Soberania Argentina sobre las Islas Malvinas, Georgias y Sandwich del Sur, (Buenos Aires, 1982). 
asumida por el gobierno argentino con los derechos de soberania de SMB sobre las islas.

Para escarmentar a los buques pesqueros, mayormente de bandera inglesa $y$ norteamericana que continuamente violaban las ordenanzas del gobernador Vernet, éste resuelve detener a 3 buques de bandera norteamericana y lleva a uno de ellos, el Harriet, a Buenos Aires para que sus tripulantes sean juzgados.

2. Desalojo de la Guarnición Argentina de Puerto Soledad

Al enterarse de la detención del buque Harriet, el cónsul norteamericano Slacum presenta un violento reclamo al gobierno argentino y amenaza con hacer intervenir a la corbeta de guerra Lexington si no se procedia a anular el juicio pendiente a los buques de su nación. Vencido el plazo otorgado por Slacum al gobierno argentino y ante la evidencia de que éste gobierno no cedería ante sus pretensiones, el cónsul americano ordena al capitán Duncan que proceda a dispersar a los pobladores del establecimiento de Puerto Soledad.

La corbeta Lexington ancla en dicho puerto el 28 de diciembre de 1831 y Duncan se encarga de arrasar con la base argentina. Posteriormente éste capitán declaró las islas "libre de todo gobierno" (19).

Esta inconducta norteamericana es aprovechada por los ingleses quienes deciden enviar al buque de guerra Clio al mando del capitán Onslow para que entre nuevamente en posesión de las islas.

El 2 de enero de 1833 Onslow ancla en Puerto Soledad, donde encuentra que la goleta argentina Sarandí comandada por el capitán José Maria Pinedo habia ido a transportar al gobernador interino de las Islas.

El Comandante inglés le exige a Pinedo la desocupación del puerto en el plazo de 24 horas alegando que el archipiélago le

(19) LA CIVILTA CATTOLICA, La Guerra per le Isole Falkland Malvine, (Anno 133, Vol II, Quaderno 3167, 1982), p. 499. 
pertenecia a $\mathrm{Su}$ Majestad Británica. Pinedo se niega rotundamente a cumplir tal exigencia y transcurrido el plazo prefijado los ingleses arrian la bandera argentina y ocupan por la fuerza Puerto Soledad.

Estos son los acontecimientos que dieron origen a la actual ocupación británica de las Islas Malvinas (20).

\section{LOS TITULOS DE SOBERANIA}

En este capitulo efectuaremos el análisis de los títulos presentados por Argentina y Gran Bretaña en la defensa del derecho que cada una afirma le asiste para ejercer la soberania plena sobre el archipiélago malvinense. Por ello, consideramos conveniente hacer una previa aclaración del mencionado concepto conocido en latin como "summa potestas".

\section{A. La Soberania}

La soberania es un concepto fundamental del Derecho Internacional que está referido a la potestad de la que goza cada Estado para sin injerencia extranjera alguna gobernarse a si mismo y dirigir plenamente sus relaciones con los demás Estados y organismos de la Comunidad Internacional.

Vemos pues, que son 2 los aspectos esenciales de la soberanía estatal (21):

(20) Para mayor información acerca de los antecedentes históricos de la Cuestión Malvinas véase:

Bonifacio DEL CARRIL, La Cuestión de las Malvinas, (Emecé Editores S.A., Buenos Aires, 1982).

MINISTERIO DE ASUNTOS EXTERIORES Y DE LA COMMON. WEALTH, Las Islas Falkland, (Londres, mayo, 1982).

THE EUROPA YEARBOOK, Falkland Islands, (Europa Publications Limited, Vol. II, London, 1978).

REVISTA INTERAMERICANA VISION, La Discordia de las Malvinas, (Vol. 59, No 4, 23 de agosto, 1982), pp. 6-10.

(21) Hildebrando ACCIOLY, Derecho Internacional Público, (Imprenta Nacional, Rio de Janeiro, T.I., 1945), p. 208. 
1. En su aspecto interno, también denominado AUTONOMIA, el Estado goza de 3 derechos básicos:

a. El derecho de organizarse politicamente, es decir, de escoger libremente la forma de gob:erno que más le convenga;

b. El derecho de dictar sus propias leyes;

c. El derecho de hacer respetar esas leyes.

2. En su aspecto externo también denominado INDEPENDENCIA, el Estado tiene el derecho de conducir libremente sus relaciones con los demás Estados, es decir, sin la intervención o injerencia de una autoridad extranjera.

La amplitud de estas atribuciones ha llegado a ser temida por algunos internacionalistas al ver la actitud negativa de ciertas naciones de evadir el cumplimiento de las normas encargadas de regir la conducta internacional de los Estados por considerarlas incompatibles con su derecho de soberanía. Al respecto, el famoso tratadista inglés James Brierly opina:

"Desgraciadamente el internacionalista no puede liberar su materia del fantasma de la doctrina de la soberania, demostrando que es uno de aquellos conceptos que se han convertido más en tiranos que en servidores nuestros (22)".

Cabe agregar sin embargo, que el concepto de soberania absoluta ha ido perdiendo fuerza en los últimos años debido al desplazamiento gradual del concepto de independencia por el de interdependencia estatal, hecho que confiamos, favorecerá y facilitará la labor del Derecho Internacional.

B. Argentina: Títulos histórico-jurídicos (23)

(22) James BRIERLY, La Ley de las Naciones, (Editora Nacional, México, 1950), p. 43.

(23) Véase DEL CARRIL, ob. cit. pp. 76-100, también:

Haroldo FOULKES, Las Malvinas. Una Causa Nacional, (Ediciones Co- 
A continuación realizaremos una enumeración cronológica y breve sintesis de los títulos en los que la República de Argentina basa su derecho de soberania sobre las Islas Malvinas.

1. La bula Inter Coetera del Papa Alejandro VI del 4 de mayo de 1493.

Por medio de ella se adjudica a la corona española todas las tierras situadas al oeste de la linea imaginaria trazada por el Papa Alejandro IV para dividir las regiones del Nuevo Mundo entre España y Portugal. Dicha linea se fija en el meridiano que pasa a 100 leguas al oeste de las Islas Azores, lo cual ubica a las Islas Malvinas dentro de la jurisdicción de España.

\section{El Tratado de Tordes llas de 1494.}

Este tratado se firma entre España y Portugal con el fin de trasladar la linea divisoria antes mencionada a 370 leguas al oeste de las Islas Azores. En todo lo demás se ratifica la concesión pontificia del año anterior.

3. El Tratado de Paz, Alianza y Comercio del 23 de mayo de 1667 .

Este tratado que celebran España e Inglaterra establece en sus artículos VI y XXIII que:

"los súbditos ingleses no navegarán ni traficarán en ninguno de los puertos, lugares, fuertes, alojamientos o castillos que posea el Rey de España. No será lícito venir a tierra, entrar o permanecer en los puertos de uno y otro, con navios y soldados, en número que pueda causar sospecha, sin licencia o permiso de aquel a quien los dichos puertos, ensenadas y playas pertenezcan (24)".

rregidor, Buenos Aires, 1982).

MINISTERIO DE RR.EE Y CULTO DE ARGENTINA, ob. cit.

José MONETA, ¿Nos devolverán las Malvinas? (Buenos Aires, abril, 1970)

U.N. CHRONICLE, The Debate Falkland-Malvinas, (Vol. XIX, № 7 , july, 1982).

(24) CARRASCO, ob. cit. p. 194. 
4. El conjunto de Tratados que firman España y Gran Bretaña en 1713 después de la guerra de sucesión española confirma la política hasta entonces seguida por ambas naciones de respetar mutuamente sus respectivas adquisiones territoriales. Estos tratados son:

4.1. El tratado preliminar de $\mathrm{Paz}$ y Amistad firmado en marzo de 1713

En él el rey de España plasma su decisión de no conceder en adelante permiso alguno para que se comercie en las Indias españolas, excepción hecha de la compañia de Asiento de $\mathrm{Ne}$ gros, la cual si estaba permitida de surtir de esclavos negros a las posesiones inglesas de ultramar.

4.2. El Tratado definitivo de Paz y Amistad firmado en Utrech el 13 de julio de 1713

En su articulo VIII confirma lo establecido en el tratado preliminar e incluso añade una alianza en la que se favorece a los intereses españoles.

Art. VIII: "Se ha convenido y establecido especialmente, que por ningún título, ni con ningún pretexto se pueda directa ni indirectamente conceder jamás licencia ni facultad alguna a los franceses ni a otra nación para navegar, comerciar, ... en los dominios de América pertenecientes a España. Y al contrario, para que se conserven más enteros los dominios de la América Española. promete la reina de Gran Bretaña que solicitará y dará ayuda a los españoles para que los límites de sus dominios de América se restituyan y se fijen como estaban al tiempo del referido rey Católico Carlos II (25)".

La actitud de desconfianza que se había adueñado de el pueblo británico ante el avance y fortalecimiento del poderío colonial francés explica la razón de ser de este artículo. A su vez, reitera el expreso reconocimiento del gobierno británico de todas las posesiones territoriales de España en América. 
4.3. El Tratado de Paz, Amistad y Comercio firmado en en marzo de 1713.

Por medio de este tratado se ratifica el Tratado de Madrid de 1667.

5. El Tratado de París firmado el 10 de febrero de 1763.

Este tratado se celebra entre España y Francia de un lado y Gran Bretaña del otro. Mediante él se pone fin a la guerra de los 7 años. En su artículo II se corrobora la vigencia de todos los tratados suscritos anteriormente entre las coronas británica y española.

6. E1 expreso reconocimiento que efectúa Francia de los derechos españoles sobre las Islas Malvinas en el mes de abril de 1767

Este reconocimiento que se materializa con el traspaso del establecimiento francés de Port Luis a la corona española, no origina las protestas de ninguna nación europea, hecho que implicaria un tácito reconoc:miento de los derechos españoles sobre el archipiélago malvinense por parte de aquellas naciones que guardaron silencio.

7. El Tratado de San Lorenzo o Nootka Sound Convention celebrado el 28 de octubre de 1790 entre Gran Bretaña y España

Situándolo dentro de su contexto histórico podemos ver cómo este tratado está dirigido entre otras cosas a dar por terminada cualquier pretensión britânica sobre las Islas Malvinas. Veamos lo que establece su articulo VI:

"Se ha convenido también por lo que hace a las costas tanto orientales como occidentales de la América Meridional y las islas adyacentes que los súbditos respectivos no formarán en lo venidero establecimiento en las partes de estas costas situadas al sur de las partes de las mismas costas y de las islas adyacentes ya ocupadas por España. Bien entendido que los dichos súbditos respectivos conservarán la facultad de desembarcar en las costas e islas asi situadas, para los objetos de pesca, y 
de levantar cabañas y otras temporales que sirvan solamente a estos objetos (26)".

\section{El Uti Possidetis}

Al producirse la independencia de Argentina en 1810, ella entra en la sucesión de todos los derechos que España tenía hasta ese momento sobre las Provincias Unidas del Rio de la Plata. Para delimitar sus fronteras Argentina aplica la doctrina del Uti Possidetis, la cual consiste en admitir como limites de la nueva $\mathrm{Re}$ pública aquellos fijados por las Reales Cédulas para sus circunscripciones administrativas.

Las Islas Malvinas, incorporadas a la Capitania General de Buenos Aires por Real Cédula del 4 de octubre de 1766, formaban parte integrante del territorio que Argentina heredaba.

\section{La Teoria de la Contigüidad Geográfica}

De acuerdo a esta teoria que responde a criterios de conservación y defensa, se le asigna a un Estado un derecho preferente de soberania sobre las prolongaciones naturales del territorio que ocupa.

Las Islas Malvinas forman parte de la plataforma continental argentina, de alli que aplicando la teoria de la contigüidad geográfica se añadiria un título más a favor de la tesis argentina.

Un estudio más detenido de los títulos hasta aquí mencionados será llevado a cabo en la sección " $D$ " del presente capítulo.

C. Gran Bretaña: Títulos histórico-jurídicos (27)

(26) Fernando DIAZ-PLAJA, La Historia de España en sus Documentos (Instituto de Estudios Politicos, Madrid, 1955).

(27) Véase REFERENCE SERVICES, Central Office of Information, London, The Falkland Islands and Dependencies, (London, 1982), también:

MINISTERIO DE ASUNTOS EXTERIORES Y DE LA COMMONWEALTH, Las Islas Falkland, (Londres, mayo de 1982). 
Los títulos y argumentos fundamentales en los que el Reino Unido de Gran Bretaña e Irlanda del Norte basa sus alegados derechos territoriales sobre las Islas Malvinas son:

1. La prioridad de descubrimiento y primer desembarco cier. to de que se tenga noticia efectuados por los capitanes ingleses John Davis y John Strong en los años de 1592 y 1690 respectivamente.

2. El reconocimiento español de los derechos británicos sobre el archipiélago malvinense derivado de la devolución de Port Egmont a Gran Bretaña en 1771.

3. La reserva del derecho británico de soberanía sobre las Islas Malvinas efectuada en 1774 por los súbditos británicos con ocasión de dejar las Islas.

Esta reserva se imprime en una placa de plomo con la siguiente inscripción:

"Sépase por todas las naciones que la isla Falkland, con este fuerte, almacenes, ... tiene un solo dueño y propietario, la Sagrada Majestad de Jorge III, Rey de Gran Bretaña (28)".

4. La ocupación abierta, efectiva, contínua y pacífica que Gran Bretaña ejerce desde 1833 sobre el archipiélago malvinense.

Gran Bretaña sostiene que si antes de 1833 podian caber dudas acerca del titular de los derechos de soberanía sobre las Islas Malvinas, después de 150 años de ocupación ininterrumpida estas dudas se despejan en aplicación de la institución de la prescripción adquisitiva.

5. Por último, Gran Bretaña sostiene que la decisión sobre el destino de las Islas Malvinas le corresponde en última instancia a la población malvinense en aplicación del derecho de libre determinación de los pueblos.

(28) BRLINO BOLOGNA, ob. cit. p. 428. 
En vista del manifiesto deseo de los isleños de seguir manteniendo su actual estatuto constitucional de colonia británica, Gran Bretaña ha decidido no apoyar la transferencia de la supremacía que ejerce sobre las Islas, hecho que contrariaria la expresa voluntad del pueblo malvinense.

Este último punto, al ser materia de debate en el seno de las Naciones Unidas, será analizado por separado y con mayor detenimiento en el capitulo III de nuestro trabajo.

D. Confrontación y Valoración de los titulos Argentinos e Ingleses

En esta sección realizaremos el estudio analítico de los titulos argentinos e ingleses siguiendo el orden en que fueron apareciendo en la historia. Las normas y principios del Derecho Internacional Público se aplicarán para concluir en la validez o invalidez de cada título.

1. La Bula pontificia de 1493 y el Tratado de Tordesillas de 1494 .

En los siglos XV y XVI se podia atribuir territorios a los Estados colonizadores por medio de concesiones pontificias. Estas concesiones o bulas pontificias podían ser el resultado de una labor de arbitraje en una disputa territorial o podian ser simplemente privilegios o gracias concedidas por el sumo pontífice a naciones que él quería favorecer por uno u otro motivo.

¿Qué valor tienen estas bulas para el Derecho Internacional?

El ilustre tratadista chileno-venezolano del siglo pasado, Andrés Bello, responde esta pregunta al afirmar:

"...pero, estas concesiones pontificias, lo mismo que las convenciones que sobre éste asunto intervinieron entre las potestades seculares no fueron respetadas por la Gran Bretaña, ni por la Francia i Holanda, i en el 
dia, las referidas bulas son letra muerta, a no ser en las cuestiones de limites entre Portugal i España (29).

La bula pontificia, asi como el posterior tratado que lo ratifica, se dieron con el fin de resolver un problema limitrofe entre España y Portugal, en consecuencia, por ellos quedaban obligadas solamente esas dos naciones.

2. El descubrimiento inglés de las islas y el posterior desembarco de Strong

El descubrimiento por si solo es un hecho que no origina derechos de soberania a menos que sea seguido por una ocupación efectiva. Para que una operación sea considerada como efectiva debe cumplir con dos condiciones esenciales:

a. debe ser realizada ánimo domini, es decir, con la intención de adquirir competencia sobre el territorio ocupado;

b. debe ser material, es decir, que se realicen actos de administración y gobierno en el territorio ocupado.

El descubrimiento, por las complicaciones que presenta su de, terminación sólo puede proporcionar un derecho embrionario "inchoate title" a quien lo realiza, y requiere del ejercicio de la posesión para ser perfeccionado (30).

Gran Bretaña, al no haber seguido su descubrimiento con una ocupación efectiva de las Islas, no puede basar su derecho de soberania en dicho acto.

3. El Tratado de Paz, Alianza y Comercio de 1667 y los Tratados de Utrech de 1713

¿Podemos calificar como juridicamente vinculatorios a esta serie de tratados firmados entre España y Gran Bretaña?

(29) Andrés BELLO, Principios de Derecho Internacional Público, (Atalaya Ed., Buenos Aires, 1946), p. 53.

(30) Charles ROUSSEAU, Derecho Internacional Público, (Ediciones Ariel, Barcelona, 1966), p. 243. 
A partir del siglo XVI, siglo de los grandes descubrimientos territoriales, se procura fijar las reglas a ser aplicadas en la adquisición de las regiones sin soberano. Para esos efectos. las naciones colonizadoras recurren al Tratado, instrumento jurídico, regulador de las relaciones internacionales por excelencia, desde la aparición del Derecho Internacional.

La incertidumbre y la desconfianza reinaban entre las grandes potencias maritimas de la época, a decir, Gran Bretaña. España, Francia, Portugal y Holanda; todas ellas con iguales ambiciones expansionistas. Por ello, estas naciones se veian obligadas a recurrir con bastante frecuencia a la celebración de tratados. Estos fijaban "las reglas del juego" para el establecimiento de la competencia sobre los territorios res nullius y garantizaban el respeto de los acuerdos a que se llegaba entre los gobiernos.

Andrés Bello, refiriéndose a la fuerza vinculatoria de los mencionados instrumentos jurídicos afirmaba:

"Los tratados son leyes que obligan a los súbditos de cada uno de los soberanos contratantes" (31).

Por eso, si Gran Bretaña aceptaba a través de la firma de tratados la jurisdicción de España sobre las Indias Occidentales, incluidas en ellas las Islas Malvinas, ella quedaba obligada en adelante a respetar esa jurisdicción.

4. El expreso reconocimiento francés de los derechos españoles sobre las Islas Malvinas

Efectuado el traspaso de la posesión francesa al gobierno español en 1767 y publicado en Europa el libro "Viaje alrededor del mundo por la fragata del rey" escrito por Bougainville, en el cual se reconocia la soberanía española sobre las Islas Malvinas, Gran Bretaña no protesta ni procura reivindicar derecho de propiedad alguna, pudiendo interpretarse válidamente esta actitud como una aceptación tácita del derecho español.

(31) BELLO, ob. cit. p. 30 . 
5. La restitución española de Port Egmont a Gran Bretaña en 1771

Como vimos en el capitulo I de nuestro trabajo, en las ne. gociaciones habidas entre España y Gran Bretaña por causa del violento desalojo de los súbditos británicos de Port Egmont, lo que en el fondo se perseguia era reparar la ofensa inferida al honor británico.

España no sólo desconoció derechos británicos sobre las islas, sino que por encima de todo, dejó bien sentado su derecho anterior de soberania sobre las Islas Malvinas al firmar la declaración que, desagraviando a Gran Bretaña, ordenada la restitución de las cosas en Port Egmont al statu quo ante. La declaración firmada por España se limitaba a resolver una cuestión de hecho y de ninguna manera representó un reconocimiento por parte de España de derechos británicos sobre las Malvinas.

6. La reserva del derecho de soberania británjco sobre las Malvinas. 1774

Esta reserva impresa en una placa de plomo en momentos en que los súbditos británicos procedian a abandonar las islas, no es considerada en Derecho Internacional como una manera de ejercer la posesión. El dejar placas, banderas u otros emblemas distintivos de una nación configura la llamada "posesión simbóli ca", la cual no puede considerarse mantenida frente a actos exteteriores y contínuos (32) como aquellos efectivamente ejercidos por España sobre las Islas Malvinas durante casi 46 años.

Además, considerando que la decisión inglesa de abandonar las islas en 1774 respondia al compromiso adquirido 3 años antes con España, lo cual se deduce de la lectura de los documentos extraídos por el profesor argentino Raúl Martínez Moreno del Archivo Histórico de Madrid, podemos concluir que en 1774 los ingleses procedieron "animus derelinquendi", es decir, con la intención de abandonar definitivamente la cosa, convirtiendo de esa manera su posesión simbólica en un acto intrascendente.

(32) BELLO, ob. cit. p. 52. 
Por este tratado, Gran Bretaña se obligaba a no formar cin adelante establecimiento alguno en las costas 0 islas adyacentes situadas al sur de las costas de la América Meridional ya ocupadas por España. Al firmarse este tratado España llevaba ya 23 años de ocupación éfectiva de las Malvinas, y Gran Bretaña llevaba 16 de haberlas abandonado. Suponiendo que Gran Bretaña hubiera realmente tenido alguna vez derechos sobre el archipiélago malvinense, con la celebración de éste tratado quedaba en claro su intención de renunciar a ellos, puesto que las islas se hallaban comprendidas en el ámbito de aplicación del mismo.

\section{Aplicación del Uti Possidetis.}

E1 Uti Possidetis fue un interdicto posesorio del derecho romano en virtud del cual, en caso de existir un litigio por la propiedad de una cosa, se reconocía la continuación de la posesión de quien estuviera poseyendo la cosa, hasta producida la resolución del litigio (33).

A principios del S. XIX, llegado el momento de emanciparse de España, las colonias hispano-americanas fueron constituyéndose sucesivamente en estados soberanos, encontrándose al mismo tiempo en la necesidad de adoptar una regla jurídica para fijar sus respectivos limites y para no dejar a la conquista entre sí mismos "la facultad de señalar con la espada la geografía politica del nuevo mundo" (34).

Es por ello que estas nuevas naciones, recogiendo la institución romana anteriormente mencionada, se formaron respetando las demarcaciones de los virreinatos, presidencias y capitanías generales coloniales. Mediante la adopción de esta regla juridica conocida como Uti Possidetis se cumplia con garantizar el equilibrio internacional y la conservación de las soberanias de las naciones hispanoamericanas.

(33) Alberto ULLOA SOTOMAYOR, Derecho Internacional Público, (Ediciones Iberoamericanas S.A., Madrid, 1957), p. 463.

(34) Vicente G. QUESADA, Derecho Internacional Latino-Americano, T. I, (La Cultura Argentina, Buenos Aires, 1918), pp. 42-43. 
¿Hubo algún reconocimiento por parte de Gran Bretaña de éste principio del Uti Possidetis?

El 2 de febrero de 1825 un ministro inglés, Lord Parish, celebró y firmó en nombre de S.M.B. el Tratado de Amistad, Comercio y Navegación con el gobierno de las Provincias Unidas del Río de la Plata, en cuyo artículo II se estableceria:

"Habrá entre todos los territorios de S.M.E. en Europa y los territorios de las Provincias Unidas del Río de la Plata una recíproca libertad de comercio (35)".

¿Qué era lo que en Gran Bretaña se entendía por "los territorios de las Provincias Unidas del Rio de la Plata"?

Parish respondió a esta interrogante en su obra "Buenos Aires y las Provincias Unidas del Rio de la Plata", al afirmar en su introducción que:

“.. las obras de un interés histórico, relativas a los
países que en un tiempo formaron el virreinato, y aho-
ra, la República del Rio de la Plata ... (36)".

Cabe agregar que la aplicación del principio de Uti Posside. tis no fue cuestionada por nación europea alguna debido fundamentalmente a la función armonizadora y preventiva de conflictos entre las nacientes naciones americanas que cumplió éste principio.

Podemos afirmar válidamente entonces que Argentina una vez independizada de la madre patria, entró legitimamente a sucederla en todos los derechos que ésta habia tenido sobre las Provincias Unidas del Río de la Plata, incluyendo aquellos referidos a las Islas Malvinas.

(35) Ibid, p. 189.

(36) Ibid, p. 190. 
9. La ocupación británica de las Islas Malvinas

Gran Bretaña sostiene actualmente que la ocupación abierta, continua, efectiva $y$ pacifica que ha venido ejerciendo desde hace 150 años en el archipiélago malvinense le otorga el derecho a invocar la prescripción adquisitiva a su favor.

Recordemos los requisitos establecidos por el Derecho Internacional para poder invocar la prescripción adquisitiva o usucapión (37):

a. La existencia de una ocupación ininterrumpida por un extenso número de años,

b. La buena te del poseedor,

c. El silencio del legítimo propietario, es decir, su descuido en hacer valer sus derechos.

Gran Bretaña recurrió al uso de la fuerza hace 150 años para originar su ocupación de las Islas Malvinas, contraviniendo así el segundo requisito establecido para que la usocapión opere. No es dable legitimar un acto que ha sido efectuado por un medio repudiado por la doctrina y la jurisprudencia internacional. Cabe citar al respecto, las opiniones de dos destacados internacionalistas del siglo pasado, contemporáneos a los sucesos de fuerza objeto de discusión. Ellos son Andrés Bello y Emerich Vattel.

Refiriéndose a los modos de adquirir la competencia territorial, el primero afirmaba:

"Cuando una nación encuentra un país inhabitado $i$ sin dueño, puede apoderarse de él legítimamente, i una vez que ha manifestado hacerlo así, no es lícito a las otras despojarla de esta adquisición (38)".

Vattel, opinando acerca del uso de la fuerza en el campo de las relaciones internacionales afirmaba:

(37) ROUSSEAU, ob. cit. pp. 244-245.

(38) BELLO, ob. cit. p. 51. 
"...los que acuden a las armas sin necesidad, son plagas del género humano; son unos bárbaros, enemigos de la sociedad y rebeldes de las leyes de la naturaleza (39)".

En lo que se refiere al tercer requisito, sabemos que para que la prescripción adquisitiva opere a favor de un Estado, es necesario que la extintiva opere en contra de otro. Ello se debe a que el ordenamiento jurídico sanciona el descuido del propietario en hacer valer sus derechos. En el caso de Argentina esto no es lo acontecido.

La República de Argentina ha venido reclamando en forma constante su derecho de soberanía sobre las Islas Malvinas. Como consta en la Memoria de Relaciones Exteriores de la Repüblica de Argentina de 1888, en ese año el canciller argentino Quirno Costa, frente a la actitud arbitraria británica de cerrar toda posibilidad de negociación con Argentina, declaró:

"... el gobierno argentino mantiene su protesta... que no obstante la resolución de Gran Bretaña de negarse a discutir... el gobierno de la República no cree comprometidos sus legítimos derechos por aquella declaración, ni menos por el silencio que el inglés guarda; el gobierno argentino mantiene y mantendrá siempre sus derechos a la soberania de las Islas Malvinas".

Hecha la reserva de sus derechos soberanos, el gobierno argentino no ha dejado de mantener periódicas reclamaciones ante el gobierno británico.

Nosotros consideramos que estas reclamaciones conjuntamente con el apoyo y reconocimiento otorgado a Argentina por un elevado número de naciones de la Comunidad Internacional (40), impiden la operación de la prescripción adquisitiva a favor de Gran Bretaña.

(39) MARTINEZ MORENO, ob. cit., p. 518.

(40) El Comité Juridico Interamericano reconoce los derechos de soberania de la República de Argentina sobre el archipiélago malvinense en su Declaración del 16 de enero de 1976. 


\section{La Contigüidad Territorial}

En materia de adquisición de la competencia territorial de una isla, un archipiélago o de las regiones polares, el Derecho Internacional le asigna a la vecindad geográfica la función de otorgarle a un Estado determinado un título preferente de soberanía sobre las prolongaciones naturales del territorio que ocupa (41).

Fuera de los casos en los que existe un tratado que la considera específicamente, la contigüidad se considera como titulo actual y efectivo para el ejercicio de la soberanía territorial. Unicamente cuando se trata de regiones polares.

Las Islas Malvinas no se encuentran juridicamente comprendidas dentro de las mencionadas regiones polares. $\mathrm{Ni}$ hay tratado específico sobre ellas. De ahi que la República de Argentina no pueda invocar sino como titulo preferente de sobera nia éste modo geográfico de adquisición territorial.

\section{E. La Distinción entre Soberanía y Supremacia Territorial}

A pesar de corresponderle a Argentina el ejercicio del derecho de soberania sobre las Islas Malvinas, es el Reino Unido de Gran Bretaña e Irlanda del Norte el que lo viene ejerciendo desde hace ya siglo y medio. tánica?

¿Cómo califica el Derecho Internacional esta ocupación bri-

Para responder a esta pregunta, debemos previamente hacer una distinción conceptual entre la soberanía y la supremacia territorial.

El Derecho Internacional deriva su clasificación de los derechos territoriales del concepto romano de propiedad. De alli que quepa establecer la analogia:

(41) ROUSSEAU, ob. cit., pp. 252-254. 
soberania es a propiedad como supremacia es a posesión (42).

La soberanía, al igual que la propiedad, confiere a su titular un derecho de disposición en principio ilimitado sobre el objeto adquirido, genera un derecho erga omnes.

La supremacía, al igual que la posesión, está referida básicamente al ejercicio de ese derecho de propiedad a través del dominio o señorio de un Estado en determinado espacio territorial, y puede ser éste un ejercicio juridico o antijurídico dependiendo de si está basado en la autorización del Estado territorial o no.

Si bien la soberania territorial no puede originarse sin haber existido previamente una supremacia territorial, una vez adquirida esa soberania, no siempre se puede ejercer efectivamente el dominio territorial. Cabe entonces hablar de estos dos conceptos en forma separada, ya que cada uno tiene un significado $y$ valor propio.

Gran Bretaña ha venido ejerciendo una supremacia territorial antijurídica sobre las Islas Malvinas, ya que nunca contó con la autor zación de Argentina para detentarla.

¿Puede esta supremacia ancijurídica dar origen al derecho de soberania territorial por el transcurso de los años?

La respuesta que a esta interrogativa da Alfred Verdross es categórica:

... lo cual pone de manifiesto el error de quienes creen que todo señorío ejercido ánimo domini da lugar a la soberania territorial sobre el territorio ocupado, confundiendo el ejercicio efectivo de la supremacia territorial, fundado en el propio ordenamiento juridico del ocupante, y el derecho a la soberania territorial. fundado en el Derecho Internacional" (43).

(42) VERDROSS, ob. cit., pp. 202-207.

(43) Ibid, p. 222 
Es asi que cuando Gran Bretaña afirma que no desea apoyar una transferencia de soberanía territorial en contra de la voluntad del pueblo malvinense, queriéndose referir con ello a que no cederá su dominio sobre las islas, se expresa mal, ya que ella no puede transferir un derecho que no tiene. Lo que Gran Bretaña está obligada a transferir es ese señorio que Argentina se ha visto impedida de ejercer debido al comportamiento antijurídico hasta ahora tenido por aquella.

Para concluir este capitulo citaremos una vez más las palabras del renombrado internacionalista Alfred Verdross por considerarlas aplicables a la situación de Argentina con respecto a las Islas Malvinas:

“. aún en una soberanía territorial reducida a un nudum jus, subsiste el germen de la supremacia territorial, pues esta resurge automáticamente en cuanto cesa la supremacia territorial del ocupante. Cabe decir en verdad que incluso un soberano territorial que ya no pueda ejercer en acto la supremacía sobre un determinado territorio, sigue en posesión de una supremacia territorial potencial. toda vez que volverá a ser actual en cuanto desaparezca la extraña (44)".

\section{LA CUESTION DE LAS ISLAS MALVINAS EN LAS NACIONES UINIDAS}

\section{A. Ubicación de la Controversia}

En el Capítulo XI de la Carta de las Naciones Unidas se establecen los principios que deben regir a los paises miembros de las Naciones Unidas bajo cuya administración se encontraren los pueblos de los denominados Territorios No Autónomos, en su deber de promover el desarrollo del gobierno propio en dichos pueblos.

Las Islas Malvinas desde un primer momento fueron incluidas en la nómina de los territorios no autónomos por su po-

(44) Ibid., p. 207. 
tencia administradora, el Reino Unido de Gran Bretaña e Irlanda del Norte.

De otro lado, la República de Argentina en la Conferencia realizadà en San Francisco previamente a la suscripción de la Carta de las Naciones Unidas se preocupó por formular expresa reserva de sus derechos de soberanía sobre las Islas Malvinas. Tan pronto como Gran Bretaña, cumpliendo con lo dispuesto por el Artículo 73 (e) de la Carta, comenzó a transmitir información sobre la situación económica, social y educativa en las Malvinas, Argentina hizo notar a la Asamblea General de las Naciones Unidas que esa información que proporcionaba Gran Bretaña con relación a las Malvinas en nada afectaba su soberania sobre dicho territorio (45).

Cuando en 1960 se aprueba la Resolución 1514 (XV) conocida como la Declaración sobre la Concesión de la Independencia a los Países y Pueblos Coloniales, se crea un Comité Especial encargado de examinar la aplicación de esta resolución con el fin de contribuir a la aceleración del proceso de descolonización en el mundo. Este Comité denominado "El Comité de los 24", encomendó al Subcomité III examinar todo lo relativo a la Cuestión Malvinas.

Reconocida la existencia de un problema colonial dentro del ámbito de la reivindicación territorial argentina de las Islas Malvinas, comienza en el seno del subcomité III el debate sobre las alternativas de solución aplicables a la controversia anglo-argen tina.

Gran Bretaña sostiene en el debate que en aplicación del derecho de libre determinación contenido en el punto 2 de la parte declarativa de la resolución 1514 (XV) y conforme a lo dispuesto por el Artículo $73^{\circ}$ de la Carta (46), corresponde a los

(45) Del Carril, ob. cit., p. 85 .

(46) Articulo 73. Los Miembros de la Naciones Unidas que tengan o asuman la responsabilidad de administrar territoros cuyos pueblos no hayan alcanzado todavía la plenitud del gobierno propio, reconocen el principio de que los intereses de los habitantes de esos territorios están por encima de todo,.. 
pobladores de las Islas Malvinas determinar el destino del archipiélago. En el mismo tenor, Gran Bretaña sostiene que una vez expresada la voluntad de los isleños, tanto Argentina como ella están en el deber de respetarla (47).

Argentina por su parte sostiene que, es el principio de la integridad territorial contenido en el punto 6 de la resolución 1514 (XV), el que debe ser aplicado en la resolución definitiva de la controversia. Resolver el problema colonial que presenta la cuestión de las Malvinas mediante la entrega del archipiélago a otro pueblo o pais que no fuese su legitimo soberano, seria contravenir con lo dispuesto por el punto 6 de la Declaración, legitimando en este caso un acto de fuerza perpetrado por Gran Bretaña hace 150 años en su apropiación de las islas.

Expuestas de esta manera las dos alternativas concebidas para poner fin a la histórica controversia anglo-argentina, el subcomité III, el 18 de setiembre de 1964 aprueba por unanimidad las conclusiones $y^{i}$ recomendaciones siguientes:

--- El Subcomité confirma que las disposiciones de la Declaración sobre la concesión de la independencia a los países y pueblos coloniales son de aplicación al Territorio de las Islas Falkland (conocidas también con el nombre de Islas Malvinas);

- El Subcomité toma nota de la existencia de una disputa entre los gobiernos del Reino Unido de Gran Bretaña e Irlanda del Norte y de la Argentina a propósito de la soberania de las Islas Falkland (conocidas también con el nombre de Islas Malvinas);

-- El Subcomité recomienda al Comité Especial que invite a los gobiernos del Reino Unido y de la Argentina a entablar negociaciones a fin de encontrar una solución pacifica a este problema, teniendo debidamente en cuenta las disposiciones y los objetivos de la Carta de las Naciones Unidas y de la Resolución $1514(\mathrm{XV})$ así como los intereses de la población de dichas Islas

(47) MINISTERIO DE ASUNTOS EXTERIORES Y DE LA COMMONWEALTH, ob. cit., pp. 6-9. 
y también las opiniones expresadas en el curso del debate general;

- El Subcomité recomienda al Comité Especial que invite a los dos gobiernos arriba mencionados que informen al Comité Especial o a la Asamblea General del resultado de sus negociac'ones.

30a. sesión

Estas recomendaciones y conclusiones se incorporan sin mayores modificaciones en la Resolución 2065(XX) del 16 de diciembre de 1965, quedando de esta manera la Cuestión de las Islas Malvinas encuadrada en los términos de la Resolución 1514 (XV).

B. La Descolonización

1. Alcances de la Resolución 1514(XV)

El objetivo de la Resolución 1514(XV) se encuentra claramente enunciando en el párrafo 12 de su texto, el cual establece:

La Asamblea General proclama solemnemente la necesidad de poner fin rápida e incondicionalmente al colonialismo en todas sus formas y manifestaciones.

Seguidamente, en los 7 puntos que constituyen la parte declarativa de esta resolución, la Asamblea General define los principios a ser aplicados en la consecución del objetivo por ella trazado.

Se puede sintetizar el contenido de estos 7 puntos en 2 ideas centrales:

a. El logro de la independencia en todos los pueblos dependientes, mediante el ejercicio del derecho a la libre determinación. 
Destaca de la lectura de los 5 primeros puntos de la R/ $1514(\mathrm{XV})$, que la preocupación primordial de la Asamblea General reside, no tanto en la condición politica de dependencia que pueda tener un pueblo, sino más bien, en todos aquellos factores negativos que pueda entrañar esa situación de dependencia, a decir, la denegación de los derechos fundamentales del hombre:

Punto 1. La sujeción de pueblos a una subyugación, dominación y explotación extranjeras constituye una denegación de los derechos humanos fundamentales, es contraria a la Carta de las Naciones Unidas y compromete la causa de la paz y de la cooperación mundiales.

¿Qué se entiende por la "explotación y dominación extranjera" de la que habla en este punto?

Los principios IV y V del Anexo de la Resolución 1541 $\left(X V_{1}\right)$ señalan que se presume la existencia de una situación de dependencia en un pueblo cuando su territorio está separado geográficamente del país que lo administra y es distinto de éste en su aspectos étnicos o culturales.

De todas estas consideraciones, como de la detenida lec. tura del texto de la $R / 1514(X V)$ en su conjunto, se puede inferir que la Asamblea General, representando a la mayoria de las naciones de la Comunidad Internacional, vela fundamentalmente a través de su resolución, por el respeto de los derechos que posee toda persona, es decir, que prima la preocupación por lo que constituye el factor humano $(*)$.

(*) Aunque no atañe al tema central de éste trabajo, es oportuno señalar aquí, que durante la Guerra de las Malvinas de 1982, un argumento insistentemente utilizado en el mundo contra la Argentina, fue el carácter dictatorial de su Gobierno y la grave situación, hoy admitida oficialmente, de los 16,000 desaparecidos.

Este argumento no afecta la validez de los titulos de soberania aqui discutidos, puesto que los derechos de soberania de un Estado no se ven alterados por el carácter constitucional o inconstitucional de quien detente el poder; sin embargo, es un tema presente en la discusión y necesario de afrontar y corregir para una vigencia más plena de los derechos humanos. 
Dentro de éste contexto, el ejercicio del derecho a la libre determinación se concibe como el medio más eficaz para terminar con cualquier situación de opresión e injusticia en los pueblos del mundo.

Es por eso que la Independencia constituye la meta propiciada en la Declaración sobre la Concesión de la Independencia a los Países y Pueblos Coloniales, como su propio título lo revela.

b. La segunda idea o principio que contiene la parte de. clarativa de la $R / 1514$ (XV) es la contenida en sus puntos 6 y 7 . En ellos se hace mención al respeto de la unidad e integridad terr torial de todos los paises, principio éste que teniendo un contenido muy específico, no requiere de mayores aclaraciones.

2. Aplicación de la Declaración sobre la Concesión de la Independencia a los Países y Pueblos Coloniales a la Cuestión de las Islas Malvinas

Para poder saber si el pueblo de las Islas Malvinas está sometido a esa dominación y explotación extranjera que tan decididamente busca eliminar la Asamblea General a través de la aplicación de su $R / 1514(\mathrm{XV})$, es necesario conocer los aspectos fundamentales que constituyen y conforman el sistema en que se desenvuelven los isleños.

a. Aspectos Generales de la Organización Politica. Social y Económica de la población malvinense (48)

El archipiélago malvinense conformado por 2 islas mayores: Malvina del Este o Soledad, y Malvina del Oeste o Gran Malvina; y una serie de islas menores está situado en el Atlántico Sur, dentro de la plataforma continental argentina. Su superficie total es de $11,961 \mathrm{Km} 2$.

(48) Véase principalmente DEL CARRIL, ob. cit., pp. 79-100.

ENCYCLOPAEDIA BRITANICA, History of the Falkland Islands. William Benton Publisher, Vol. 9, 1964.

MINISTERIO DE ASUNTOS EXTERIORES Y DE LA COMMOWEALTH, ob. cit. 
Gran Bretaña, al anexarse el archipiélago en 1833 le otorgó el status politico internacional de 'Colonia de la Corona Británica'. Por este motivo, el gob:erno del Reino Unido es responsable ante el Parlamento por la efectiva administración de las Islas.

En 1980, el gobierno británico realizó un censo poblacional que arrojó un total de 1813 habitantes, de los cuales 1360, es decir el $80 \%$, eran nacidos en las islas y 302 en Gran Bretaña. El pequeño número restante estaba conformado por irlandeses. uruguayos y chilenos.

Desde 1931, año en que la población llega a los 2392 habitantes, el aumento de la población se tornó nulo y hasta negativo, cosa que hoy en dia sucede solamente en muy pocas partes del mundo.

Los 1360 nativos que constituyen la población estable de las Islas son conocidos como los "kelpers", nombre que derivaron de una alga local; y a los nacidos en Gran Bretaña pero que desempeñan temporalmente funciones administrativas en las Islas, se les conoce con el nombre de "ex-patriates".

Estos ex-patriates realizan sus labores directamente para uno de dos empleadores:

-.. el gobierno británico, o

- la Falkland Islands Company (FIC), empresa que ejerce monopólicamente el comercio en las Islas.

La FIC, fundada en 1851 por un importante industrial inglés, es dueña del $46 \%$ de las tierras del archipiélago y detenta el $74 \%$ de la economía de las Islas. De las 29 estancias comerciales con las que cuenta las Islas Malvinas, solamente 4 no comercializan sus productos a través de la FIC. Esta compañia también desarrolla actividades bancarias y de cobertura de seguros maritimos.

FIC controla? 
Se la puede sintetizar en dos palabras: explotación lanera.

La lana para exportación se extrae de las 650,000 ovejas que existen en las Islas. Han habido intentos de diversificar esta monoproductora economia isleña. En el informe de Lord Shackleton que para esos fines se real zó en 1975 (49), se aconsejaba el desarrollo de una industria pesquera y la explotación de la plataforma continental malvinense para la extracción de petróleo. Estos proyectos no pudieron prosperar debido a conflicto existente entre Argentina y el Reino Unido por la soberania de las Islas, lo cual traía como consecuencia la falta de garantias necesarias para poder contar con un régimen político-económico estable que hubiese permitido conseguir las invers ones privadas requeridas para cumplir con las recomendaciones de Lord Shackleton.

En lo referido al comercio, la casi totalidad de importaciones y exportaciones provienen y están dirigidas al Reino Unido.

¿Cómo es el sistema de gobierno que existe en las Islas?

El 21 de noviembre de 1977 entra en vigor la actual Constitución malvinense, en la cual se establece el principio del sufragio universal y se reduce la edad para votar a los 18 años.

Las Islas son administradas por un Gobernador designado por la Corona, el cual cuenta con el asesoramiento de un Consejo Ejecutivo compuesto por 2 miembros designados por el Gobernador, 2 miembros 'ex officio', y otros 2 elegidos por el Consejo Legislativo. Este Consejo Legislativo está constituido a su vez por 6 miembros elegidos por sufragio universal, y 2 de oficio, y' se encuentra facultado para formular leyes para la paz, el orden y el buen gobierno del territorio. Los miembros del Consejo pueden presentar proyectos de ley o proponer mociones; la legislación es aprobada por mayoria simple.

El sistema judicial está encargado a un Tribunal de Magistrados, un Tribunal Supremo cuyo vocal es un no-residente. y un

(49) José GREÑO VELASCO, "El informe Shackleton sobre las islas Malvinas". En Rev, de Politica Internacional, No 153. Madrid, 1977. 
Tribunal de Jurisdicción Sumaria. El Tribunal de Apelaciones creado en 1965 tiene su sede en Londres.

El Consejo Legislativo es el que se ocupa de la administración cotidiana de las Islas, el comercio, los servicios sociales y la educación. Esta última es gratuita y obligatoria para los niños a partir de los 5 años. Existe ayuda financiera para los estudiantes malvinenses que desean profundizar sus conocimientos en las universidades británicas.

\section{¿Qué caracteristicas propias presenta el pueblo malvinense?}

No podemos afirmar que los malvinenses han desarrollado una cultura propia e identificable como sí ha ocurrido con otras comunidades de origen británico que se establecieron en territorios de ultramar.

El sentido de identidad de los isleños está totalmente influido por su adscripción a Gran Bretaña, ellos desean seguir manteniendo los vínculos que los une con su metrópoli, de ahi la expresión: "Keep the Falkland British".

Los pobladores de las islas son personas honestas, trabajadoras, pero que no demuestran tener mucha iniciativa ni espíritu de empresa. Existe en ellos un alto grado de aceptación del statu quo que los lleva a colindar con la apatía.

En el informe del diputado inglés Phipps, publicado en 1977 se hacian las afirmaciones siguientes acerca de la situación social de los isleños:

"Todos los principales problemas sociales, especialmente la bebida y el divorcio, provienen del aislamiento de una pequeña comunidad, estrechamente integrada. El creciente impacto del mundo exterior sobre esta comunidad está ahora creando el más urgente problema social: la emigración, principalmente hacia el Reino Unim do.

Según parecz, no es la primera vez que lo que se presentó en las islas como una visión de romántica soledad descie el Reino Unido, pronto se estrelló contra la realidad de una inacabable dieta de cordero, cerveza y 
rum, espolvoreados con ocasionales borracheras y adulterios (50)".

Es de esta manera cómo un funcionario británico describe la población a la cual Gran Bretaña le pretende conferir la enorme responsabilidad de definir la controversia anglo-argentina por las Islas Malvinas.

\section{b. Libre determinación o Integridad Territorial}

Vimos en la sección $A$ del presente capítulo cómo las dos alternativas planteadas para resolver la Cuestión Malvinas dentro de los términos de la $\mathrm{R} / 1514$ (XV) se resumían en:

1. Declarar la aplicación del derecho de libre determinación de los pueblos, dejando de esa manera la decisión sobre el destino de las islas en poder de los isleños;

2. Declarar la aplicación del principio de la integridad territorial, restituyéndole a la República de Argentina, el territorio que legitimamente viene reclamando desde hace 150 años.

Los dispositivos contenidos en algunas resoluciones de la Asam. blea General pueden ayudarnos a determinar la jerarquia de principios que debe aplicarse en la resolución de la Cuestión Malvinas. Estas son:

- R/742 (VIII) del 27 de noviembre de 1953.

En la lista III de su anexo se establece que para poder ejercer el derecho a la libre determinación de los pueblos se debe tomar en cuenta el DERECHO del país metropolitano o del territorio que ejerce la libre determinación, para cambiar el status político internacional de dicho territorio, a la luz de la consideración de si ese territorio es o no es objeto de una reclamación o litigio de parte de otro Estado.

(50) DEL CARRIL, ob. cit., p. 100. 
El no tomar en cuenta éste factor al aplicar el derecho de libre determinación entrañaria correr ciertos riesgos como aquel al que hace referencia el profesor español Leandro Rubio Garcia:

"Todo Estado con el deseo de extender su territorio podria invocar éste precedente, fortificado con argumentos étnicos, religiosos o históricos para hacer cambios territoriales favorables (51)".

_.. $\mathrm{R} / 2065(\mathrm{XX})$ del 16 de diciembre de 1965.

Esta resolución establece en su punto 1. La Asamblea General invita a los Gobiernos de Argentina y del Reino Unido a proseguir sin demora las negociaciones recomendadas por el Comité Especial, ...teniendo debidamente en cuenta las disposiciones y los objetivos de la Carta de las Naciones Unidas y de la $\mathrm{R} / 1514(\mathrm{XV})$, asi como los intereses de la población de las Islas Malvinas...

La impresión que da la forma cómo ha sido redactado éste texto es que se vela por los intereses de la población malvinense como si ese factor no estuviera contemplado en la $\mathrm{R} / 1514$. El derecho de libre determinación contenido en el punto 2 de esa resolución abarca mucho más que los intereses de una población. Este derecho otorga a su titular la facultad de darse la forma de gobierno que más le convenga y perseguir libremente su desarrollo económico, social y cultural. Entonces, con qué objeto se hace mención a los intereses de la población malvinense como si estos no estuviesen ya resguardados por el contenido de la $\mathrm{R} / 1514$ (XV). ¿No será que al redactar el texto de la R/2065(XX) la Asamblea General estaba partiendo de la inaplicabilidad del derecho de libre determinación como alternativa de solución a la Cuestión Malvinas y por esa razón se preocupó de recomendar que se tomase en cuenta los intereses de los isleños al llevarse a cabo las negociaciones entre los gobiernos de Argentina y Gran Bretaña?

La Resolución que a continuación estudiamos aclara a nues. tro modo de entender la interrogativa arriba planteada.

(51) Leandro RUBIO GARCIA, "La Autodeterminación de los Pueblos". En Revista Española de Derecho Internacional. (Vol. XI, 1958, Madrid). p. 243. 
- R/2353(XXII) del 19 de diciembre de 1967: Cuestión de Gibraltar. - Párrafo 4: Considerando que toda situación colonial que destruya parcial o totalmente la unidad nacional y la integridad territorial de un país es incompatible con los propósitos y principios de la Carta de las Naciones Unidas y especificamente con el párrafo 6 de la Resolución 1514(XV) de la Asamblea General:

Punto 3. Invita a los Gobiernos de España y del Reino Unido a reanudar sin demora las negociaciones previstas con miras a poner fin a la situación colonial en Gibraltar y a salvaguardar los intereses de la población al término de la situación colonial...

El establecer en este punto que los intereses de la población se salvaguardan al término de la situación colonial está implicando que el orden a seguir para resolver la Cuestión de Gibraltar es:

1. Acabar con la situación colonial,

2. Velar por los intereses de la población, es decir que estos intereses no constituyen el factor determinante para resolver el problema colonial en si.

Hecha esta observación, ¿podemos nosotros afirmar que en la $\mathrm{R} / 2353$ (XXII) se está configurando una jerarquia de principios en la cual prima el de la integridad territorial?

La propia resolución $1514(\mathrm{XV})$ establece en su punto 7 : Todos los Estados deberán observar fiel y estrictamente las disposiciones de la presente Declaración sobre la BASE del respeto de los derechos soberanos de todos los pueblos y de su integridad territorial.

Por todas estas consideraciones y tomando en cuenta el espiritu de la $\mathrm{R} / 1514(\mathrm{XV})$ de la Asamblea General, creemos que podemos afirmar válidamente que, el principio de la integridad territorial prevalece sobre el de la libre determinación, en especial en todos aquellos casos en que, al igual que en la Cuestión Malvinas, se pretenda otorgar el derecho de libre determinación a un pueblo que se encuentra lejos de estar en la situación de opresión tipificada en la Declaración sobre la Concesión de la Independencia a los Paises y Pueblos Coloniales. 
El pueblo de las Islas Malvinas como hemos visto antericrmente, no quiere liberarse de los vinculos que lo mantienen unido a su metrópoli.

Permitir que la población malvinense ejerza el derecho de libre determinación para conservar su status politico de colonia sería a todas luces incongruente ya que, se estaria aplicando uno de los principios contenidos en la resoluc ón $1514(\mathrm{XV})$ destinada a contribuir con la liquidación del colonialismo en todas sus formas y manifestaciones justamente a prolongar dicho sistema.

Por lo tanto, creemos decididamente que la Cuestión de las Islas Malvinas debe ser resuelta restituyéndole a la República de Argentina el territorio sobre el cual tiene legítimo derecho de soberania. 